\title{
Shading of mature leaves systemically regulates photosynthesis and leaf area of new developing leaves via hormones
}

\author{
Y.S. WU ${ }^{*, * * * * *}$, W.Z. GONG ${ }^{* * * *, *}$, Y.M. WANG ${ }^{*, * *, * * *}$, and W.Y. YANG ${ }^{*, * *, * * *,+}$ \\ College of Agronomy, Sichuan Agricultural University, Chengdu 611130, China* \\ Key Laboratory of Crop Ecophysiology and Farming System in Southwest, Ministry of Agriculture, \\ Chengdu 611130, China** \\ Sichuan Engineering Research Center for Crop Strip Intercropping System, Chengdu 611130, China*** \\ Characteristic Crops Research Institute, Chongqing Academy of Agricultural Sciences, Chongqing, \\ 402160, China ${ }^{* * * *}$
}

\begin{abstract}
In order to explore whether leaf area of developing leaves was regulated by systemic irradiance signal from mature leaves, we investigated the leaf area, leaf anatomy, photosynthesis, auxin, gibberellin, and cytokinin contents of new developing leaves in soybean growing under conditions of shaded mature leaves (MS), shaded whole plants (WS), and under full sunlight (NS). The results showed that developing leaves under MS exhibited the higher leaf area and leaf mass than that of WS. Blade thickness, palisade tissue thickness, sponge tissue thickness, cell size, cell numbers, net photosynthetic rate, stomatal conductance, transpiration rate, and cytokinin content of developing leaves under MS were lower, while auxin and gibberellin contents were higher than that of NS. These results indicate that the leaf area, leaf anatomy, and photosynthesis of developing leaves were regulated by the shading environment of mature leaves. Growth hormones may possibly act as candidate signal substances to systemic regulation of leaf area development.
\end{abstract}

Additional key words: leaf structure; photosynthesis; shade; systemic response.

\section{Introduction}

When plants are exposed to high or low light levels, they develop sun or shade leaves, respectively (Casal 2012, Gong et al. 2014, Rodríguez-López et al. 2014, Wu et al. 2017). Previous studies mainly focused on leaf structure and function in plants grown fully under high or low light. However, recent research has shown that plant leaves do not only sense and respond to their own environment but also to the environment of other leaves within the same plant (Murakami et al. 2014, Li et al. 2015). This long distance signaling from mature leaves to developing leaves is defined as a systemic irradiance signal (Karpinski et al. 1999, Lake et al. 2001). First study about systemic irradiance signal was done in cowpea; it was found that shading the expanded mature leaves decreased the stomatal index in developing young leaves of cowpea (Schoch et al. 1980). Some studies have since reported that stomatal development, leaf thickness, chloroplast development, and high light tolerance in newly developed leaves are independent of their local light in Arabidopsis thaliana (Lake et al. 2001, 2002), Sorghum bicolor (Jiang et al. 2011, Li et al. 2015), Populus trichocarpa $\times$ $P$. deltoides (Miyazawa et al. 2006), Nicotiana tabaccum (Thomas et al. 2004), and Chenopodium album (Yano and Terashima 2001). Instead these leaves were shown to be dependent on the light environment of mature leaves. However, all these studies were conducted to observe the stomatal development and leaf anatomy, but to our knowledge, no attention has been paid to whether leaf area was regulated by systemic irradiance signal.

Soybean is the fourth most widely cultivated crop throughout the world, and it is usually planted in intercropping systems (Yang et al. 2015, 2017; Liu et al. 2017). When intercropped with taller crops, soybean suffered from the shade environment, while then it was exposed to full sunlight after the harvest of the taller crop. We have found that during the shade period, soybean showed smaller leaf area; hormones might be involved in this inhibition process (Gong et al. 2014, Wu et al. 2015, Wu et al. 2017). After the taller crop was harvested, the newly developing leaves of soybean grew under full sunlight

$\overline{\text { Received }} 3$ January 2018, accepted 20 July 2018.

${ }^{+}$Corresponding author; e-mail: mssiyangwy@sicau.edu.cn.

Abbreviations: BRs - brassinolide; $C_{\mathrm{i}}$ - intercellular $\mathrm{CO}_{2}$ concentration; CTK - cytokinins; FAA - formalin-acetic acid-alcohol; $g_{\mathrm{s}}$ - stomatal conductance; GAs - gibberellins; IAA - auxin; MS - mature leaves shading; NS - full sunlight; $P_{\mathrm{N}}-$ net photosynthetic rate; SAM - shoot apical meristem; WS - whole plants shaded.

Acknowledgments: We thank teachers in our team for fruitful discussions and suggestions, we would also like to thank those who helped improve this manuscript. This research was supported by National Natural Science Foundation of China (No. 31701371).

\#These authors contributed equally to this work. 
while the existing mature leaves were grown in the shade environment. Therefore we want to know whether the leaf area of newly developing leaves is regulated by the shade environment of existing mature leaves. In this study, we analyzed the leaf area, leaf anatomy, photosynthesis, auxin, gibberellin, cytokinin, and brassinolide content of soybean plants grown under the conditions of full sunlight (NS), shading of mature leaves (MS), and shading of the whole plants (WS) to address the following questions: (1) whether photosynthesis and leaf area of newly developing leaves were regulated by shading of mature leaves, and (2) whether plant hormones regulates the leaf area under systemic irradiance signals. The results of this study can give a new perspective for understanding systemic regulation of leaf area.

\section{Materials and methods}

Plant growth: Soybean was employed in this study. The experiment was conducted at a greenhouse. The light period was maintained around $12-\mathrm{h} / 12-\mathrm{h}$ day/night irradiance by artificial light source of $400 \mu \mathrm{mol}$ (photon) $\mathrm{m}^{-2} \mathrm{~s}^{-1}$ at sunrise and sunset, a day $/$ night temperature of $35 / 2^{\circ} \mathrm{C}$ and relative humidity was $40-80 \%$ at Sichuan Agricultural University, Yaan, Sichuan province, China (29 $59^{\prime}$ N, $\left.103^{\circ} 00^{\prime} E\right)$. Sixty plastic pots $(30 \mathrm{~cm}$ in diameter, $20 \mathrm{~cm}$ in height) were used in this experiment. Five soybean seeds were sown in each pot and after germination were thinned to one plant per pot; every pot was seen as a replicate. Next, the pots were divided into two groups for the different shading treatments: 20 pots under full sunlight conditions (FS) and 40 pots for shading of the whole plants. Shaded conditions were provided by green filters ( $Q-M A X 122$, USA). Compared to FS conditions, the green filters reduced the light intensity (30\% of full sunlight) and red to far-red light ratio (0.5-0.6). After growing for further $40 \mathrm{~d}$, the plants developed four fully expanded compound leaves, and one of developing leaves (one day after it emerged) (as shown in Fig.1). Then WS treatment was divided into two sub-groups: shading whole plants (20 pots, WS) and shading mature leaves (20 pots, MS) (Fig.1). After one week, when newly developing leaves were fully expanded and matured, leaf area, leaf anatomy, photosynthesis, internode stem diameter were measured.
Leaf area and leaf mass: The soybean plants were sampled, with six plants from six pots used to measure node length, node diameter, and leaf area. All leaves were scanned using a flatbed scanner (CanoScan LiDE 200, Canon Inc., Japan), and leaf area was measured by Image $J$ 1.45s. Afterwards, the leaves were exposed to $105^{\circ} \mathrm{C}$ for $0.5 \mathrm{~h}$ and then dried to a constant mass at $80^{\circ} \mathrm{C}$ to determine their dry mass (DM).

Leaf anatomical structure: Three plants were sampled, three middle segments of middle leaflet from three new developing leaves $(5 \times 5 \mathrm{~mm})$ were cut avoiding midrib and fixed in FAA solution used for paraffin. After the capture of microphotographs (Digital Sight DS-U1, Nikon Instruments Inc., Japan), total leaf thickness, palisade tissue thickness, cell length, and cell width were measured by Image $J 1.45 \mathrm{~s}$. The cell size and density of palisade cells per unit area in the subepidermal layer were determined. Density was multiplied by the leaf area to calculate the total palisade cell number of leaf. This determination was repeated on six individuals.

Photosynthesis was measured following the method of Gong et al. (2015) using an infrared gas analysis instrument (LI-6400, Li-COR Inc., Lincoln, NE, USA) from 10:00 to 14:00 h on a sunny day. Conditions in the chamber were: PAR of $1,000 \mu \mathrm{mol}$ (photon) $\mathrm{m}^{-2} \mathrm{~s}^{-1}$, leaf temperature of $25^{\circ} \mathrm{C}$ for, relative humidity of $60-75 \%, \mathrm{CO}_{2}$ concentration of $380 \mu \mathrm{mol} \mathrm{mol}{ }^{-1}$. Photosynthetic rate $\left(P_{\mathrm{N}}\right)$, transpiration rate $(E)$, stomatal conductance $\left(g_{\mathrm{s}}\right)$, and intercellular $\mathrm{CO}_{2}$ concentration $\left(C_{\mathrm{i}}\right)$ were automatically recorded by the instrument. Three newly developing leaves from three plants were chosen to measure photosynthesis; at least three replicates for each newly developing leaves were measured under each treatment.

Plant hormone contents: When newly developing leaves reached after emergence $3 \mathrm{~d}$ (young age), three leaves were collected from three plants, wrapped in foil, and immediately frozen in liquid nitrogen. Hormone contents were determined by enzyme-linked immunosorbent assay (ELISA) according to Yang et al. (2002). Briefly, samples ( $1 \mathrm{~g}$ of fresh mass, FM) were used for an extraction of plant hormones. Antibodies against indole-3-acetic acid (IAA),

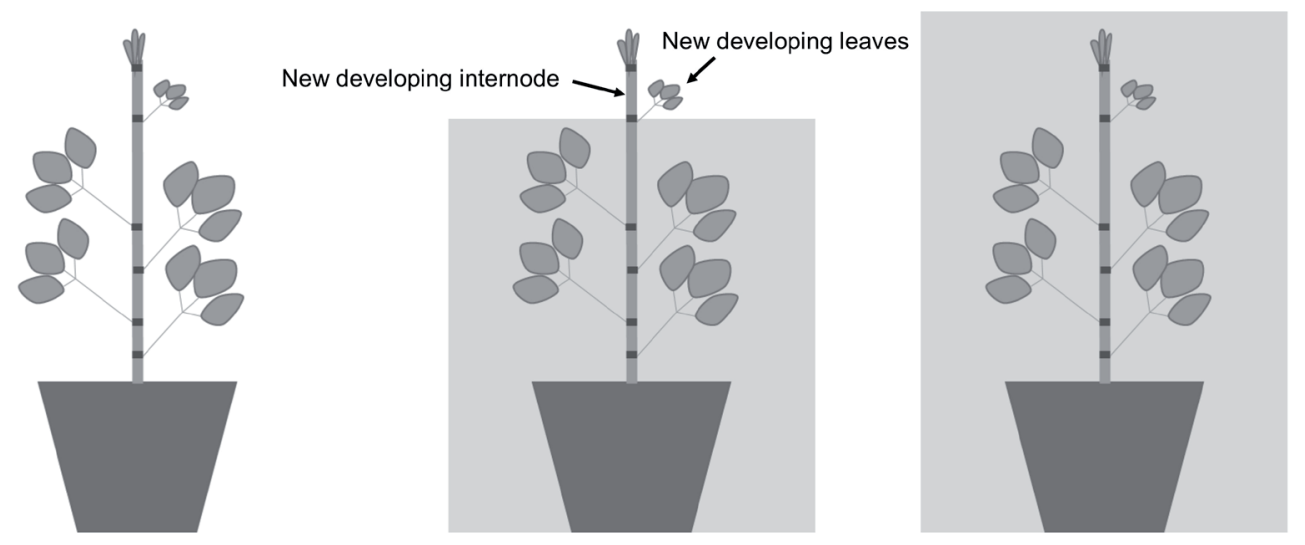

Fig. 1. Design of shading treatments. 
gibberellins (GAs), cytokinin (CTK), and brassinosteroids (BRs) were used to determine hormone contents using an ELISA reader (I8020, G8040, X8040, SB8360; Solarbio, China). ELISA kit was purchased from China Agricultural University, Beijing, China. Determination was conducted according to the manufacturer's protocol. Three biological replications were performed.

Statistical analysis: Analysis of variance $(A N O V A)$ in SPSS software 19.0 (SPSS, Chicago, USA) was used to analyse the differences between WS, MS, and NS treatments. All measured and calculated features were analysed as dependent variables. SigmaPlot 12.5 was used for all mapping.

\section{Results}

Leaf area, internode length and internode diameter in shading conditions: Leaf area (1-4) and internode diameter (1-4) in WS and MS were significantly lower than the corresponding leaves and internodes in NS, respectively. Stem length in WS and in MS were significantly higher than that of NS. There was no difference between WS and MS (Table 1).

Length and diameter of newly developing internode in MS was significantly lower than that of WS and significantly higher than that of NS. On the contrary, a diameter of newly developing internode in MS was significantly higher than that of WS and lower than that of NS (Table 2).

Leaf area and leaf mass of newly developing leaves: In this study, when newly developing leaves in three treatments fully expanded and reached maturity, we measured leaf area and leaf mass. Compared to NS, WS and MS showed a marked reduction in the leaf area and leaf mass. Leaf area and leaf mass of MS were higher than that of WS (Table 2).
Leaf anatomy of newly developing leaves: The effects of shading treatments on cross sections of the newly developed leaves are shown in Fig. 2. Blade thickness, palisade tissue thickness, sponge tissue thickness, and cell length in MS were significantly higher than that of WS and significantly lower than that of NS (Fig. 3).

We examined the cell size and number of cells at the subepidermal layer of newly developing leaves (Fig. 4). Compared to NS, WS and MS exhibited a significant decrease in the cell size and number of cells. The value of cell size and number were significantly higher in MS than those of WS.

Photosynthesis of newly developing leaves: $P_{\mathrm{N}}, g_{\mathrm{s}}$, and $E$ in newly developing leaves under MS treatment showed significantly higher values than that of WS and showed significantly lower values than that of NS (Fig. 5). However, the value of $C_{\mathrm{i}}$ exhibited a contrary trend in newly developing leaves.

Plant hormones of newly developing leaves: Compared to NS, WS and MS showed significantly increased content of auxin and gibberellins, and significantly decreased content of cytokinins in soybean leaves (Fig. 6), while there was no difference in contents of brassinolides between shaded plants (WS and MS) and FS plants (Fig. 6 D). Compared to the value of WS, the content of auxins and gibberellins significantly decreased and content of cytokinins significantly increased.

\section{Discussion}

Leaf area and anatomy generally shows a strong response to irradiance (Corre 1983). Under low irradiance, leaves tend to be smaller, then they increase in size with increasing irradiance until they reach a certain level (dependent on environment and species) after which the leaf area declines with further increases in irradiance. The results presented

Table 1. Leaf area, internode diameter, and stem length at 40 days after sowing. Values are means $\pm \operatorname{SD}(n=6)$. Statistical significance assessed by Duncan's $t$-test. Different lowercase letters mean significant difference at 0.05 level.

\begin{tabular}{|c|c|c|c|c|c|c|c|c|c|}
\hline \multirow{2}{*}{ Treatment } & \multicolumn{4}{|c|}{ Trifoliolate leaf area $\left[\mathrm{cm}^{2}\right]$} & \multicolumn{4}{|c|}{ Internode diameter $[\mathrm{mm}]$} & \multirow[t]{2}{*}{ Stem length $[\mathrm{cm}]$} \\
\hline & First & Second & Third & Fourth & First & Second & Third & Fourth & \\
\hline NS & $228.32 \pm 3.5^{\mathrm{a}}$ & $250.16 \pm 4.2^{\mathrm{a}}$ & $268.44 \pm 2.7^{\mathrm{a}}$ & $273.55 \pm 1.9^{\mathrm{a}}$ & $6.32 \pm 0.3^{\mathrm{a}}$ & $7.02 \pm 0.2^{\mathrm{a}}$ & $6.97 \pm 0.1^{\mathrm{a}}$ & $6.72 \pm 0.2^{\mathrm{a}}$ & $26.44 \pm 4.3^{\mathrm{b}}$ \\
\hline MS & $117.02 \pm 3.1^{\mathrm{b}}$ & $125.82 \pm 3.6^{\mathrm{b}}$ & $130.53 \pm 4.2^{\mathrm{b}}$ & $149.98 \pm 2.8^{b}$ & $3.07 \pm 0.3^{b}$ & $2.46 \pm 0.3^{\mathrm{b}}$ & $2.67 \pm 0.4^{\mathrm{b}}$ & $2.70 \pm 0.5^{\mathrm{b}}$ & $57.00 \pm 3.7^{\mathrm{a}}$ \\
\hline WS & $120.79 \pm 2.9^{b}$ & $129.72 \pm 2.3^{b}$ & $136.28 \pm 3.6^{\mathrm{b}}$ & $146.21 \pm 2.6^{\mathrm{b}}$ & $2.51 \pm 0.3^{\mathrm{b}}$ & $1.90 \pm 0.2^{\mathrm{b}}$ & $1.72 \pm 0.5^{\mathrm{b}}$ & $1.74 \pm 0.5^{b}$ & $58.01 \pm 4.0^{\mathrm{a}}$ \\
\hline
\end{tabular}

Table 2. Leaf area, leaf mass, internode length, and internode diameter in newly developed leaves and internodes during treatments. Values are means $\pm \mathrm{SD}(n=6)$. Statistical significance assessed by Duncan's $t$-test. Different lowercase letters mean significant difference at 0.05 level.

\begin{tabular}{lllll}
\hline Treatment & Leaf area $\left[\mathrm{cm}^{2}\right]$ & Leaf mass $[\mathrm{g}]$ & Internode length $[\mathrm{cm}]$ & Internode diameter $[\mathrm{mm}]$ \\
\hline NS & $303.63 \pm 5.78^{\mathrm{a}}$ & $1.01 \pm 0.05^{\mathrm{a}}$ & $4.32 \pm 0.71^{\mathrm{c}}$ & $4.81 \pm 0.24^{\mathrm{a}}$ \\
MS & $166.32 \pm 4.02^{\mathrm{b}}$ & $0.59 \pm 0.03^{\mathrm{b}}$ & $7.72 \pm 0.72^{\mathrm{b}}$ & $3.03 \pm 0.22^{\mathrm{b}}$ \\
WS & $151.70 \pm 3.91^{\mathrm{c}}$ & $0.32 \pm 0.03^{\mathrm{c}}$ & $12.75 \pm 0.80^{\mathrm{a}}$ & $1.63 \pm 0.23^{\mathrm{c}}$ \\
\hline
\end{tabular}




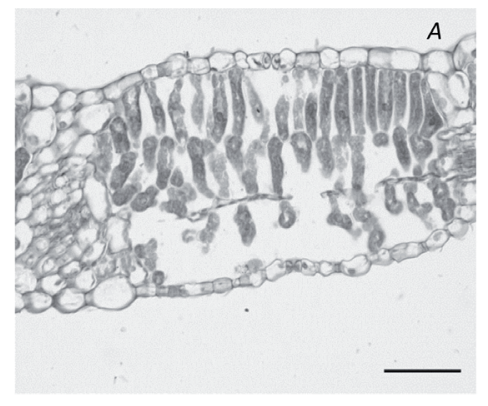

NS

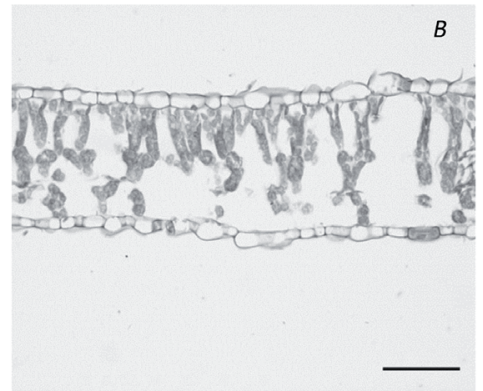

MS

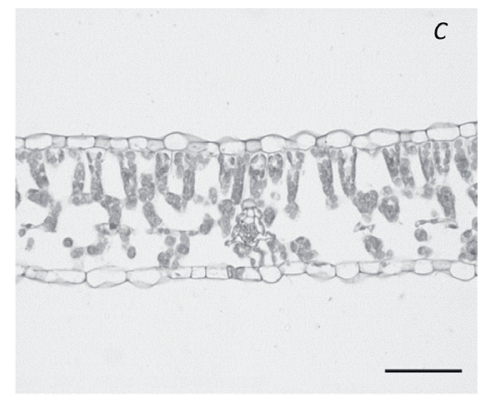

WS

Fig. 2. Cross-sections and microscope views of new developing leaves during shading treatments. Bars $-50 \mu \mathrm{m}$.

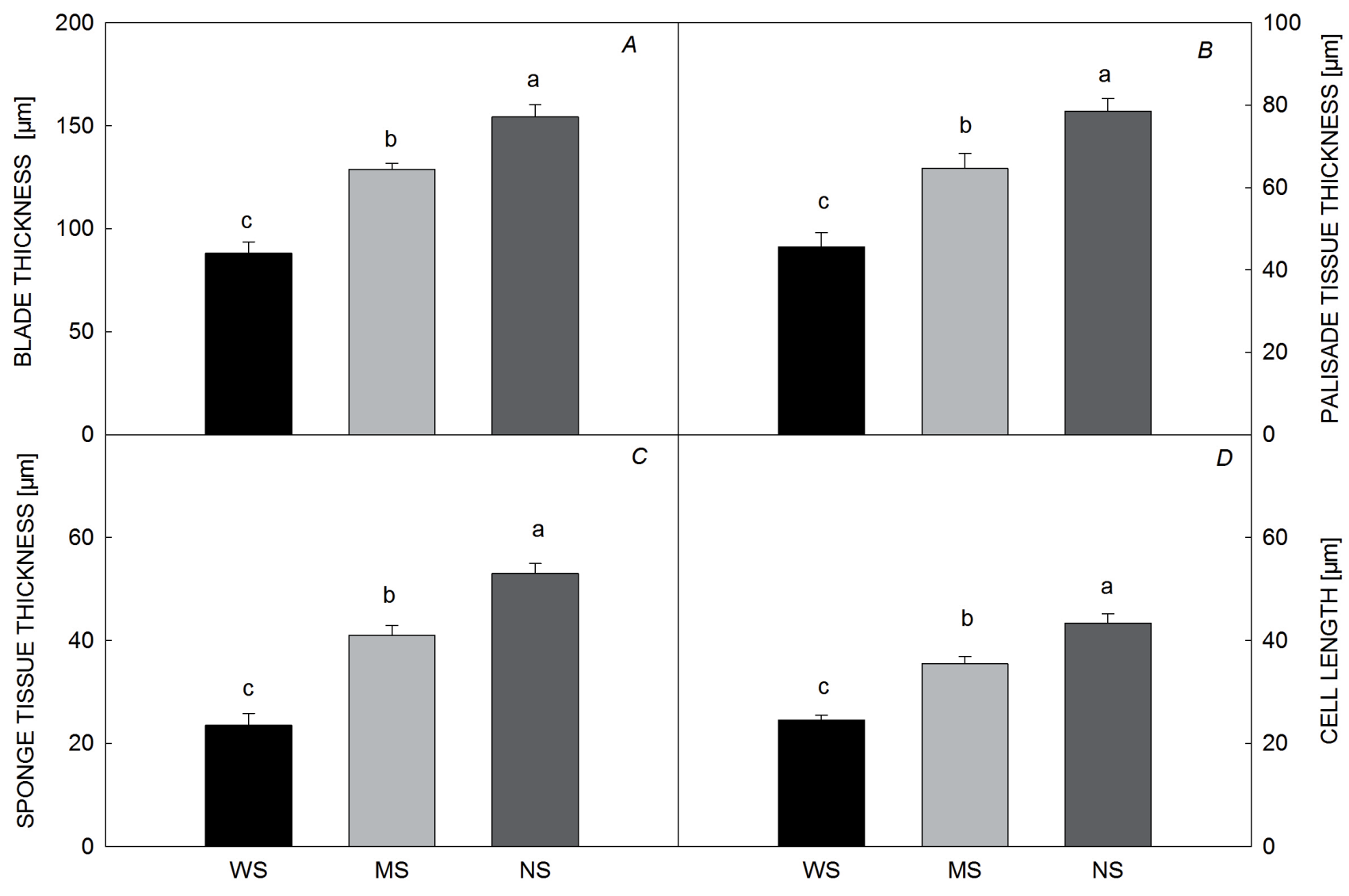

Fig. 3. Leaf blade thickness $(A)$, palisade tissue thickness $(B)$, sponge tissue thickness $(C)$, and cell length $(D)$ of newly developing leaves during shading treatments. Values are means $\pm \mathrm{SD}(n=3)$. Statistical significance assessed by Duncan's $t$-test. Different lowercase letters mean significant difference at 0.05 level.

here indicate that the leaf area of newly developing leaves was strongly influenced by the shade environment of mature leaves, as shown by the significant decrease in leaf area and in leaf mass of the newly developed leaves in MS. It resulted in a decrease in blade thickness, palisade tissue thickness, sponge tissue thickness, and cell length, although the newly developing leaves were exposed to full sunlight, the leaf anatomy showed still shade leaves with characteristics similar to those kept in a shade environment. This is consistent with previous studies that the thickness of newly developed leaves is determined by the light environment of mature leaves (Jiang et al. 2011). Besides, cell size and cell numbers of newly developing leaves in MS were lower than that of NS, which indicated that the cell size and cell numbers of the developing leaves might be affected by the shade environment of the mature leaves. In addition, shading of the whole plants reduced $P_{\mathrm{N}}$ of newly developing leaves. But under the MS treatment, plants were grown in the shade from the beginning and the newly developing leaves actually experienced the increase of light intensity; they showed photosynthetic light acclimation along with the increased $P_{\mathrm{N}}$. As reported in some previous studies, many plants increase photosynthetic capacity of leaves when they are transferred from low light to high light (Azevedo and Marenco 2012, Avalos and Mulkey 2014). Photosynthesis is determined by stomatal or nonstomatal limitations, and only when the $C_{\mathrm{i}}$ and $g_{s}$ decrease simultaneously, it is supposed that the 


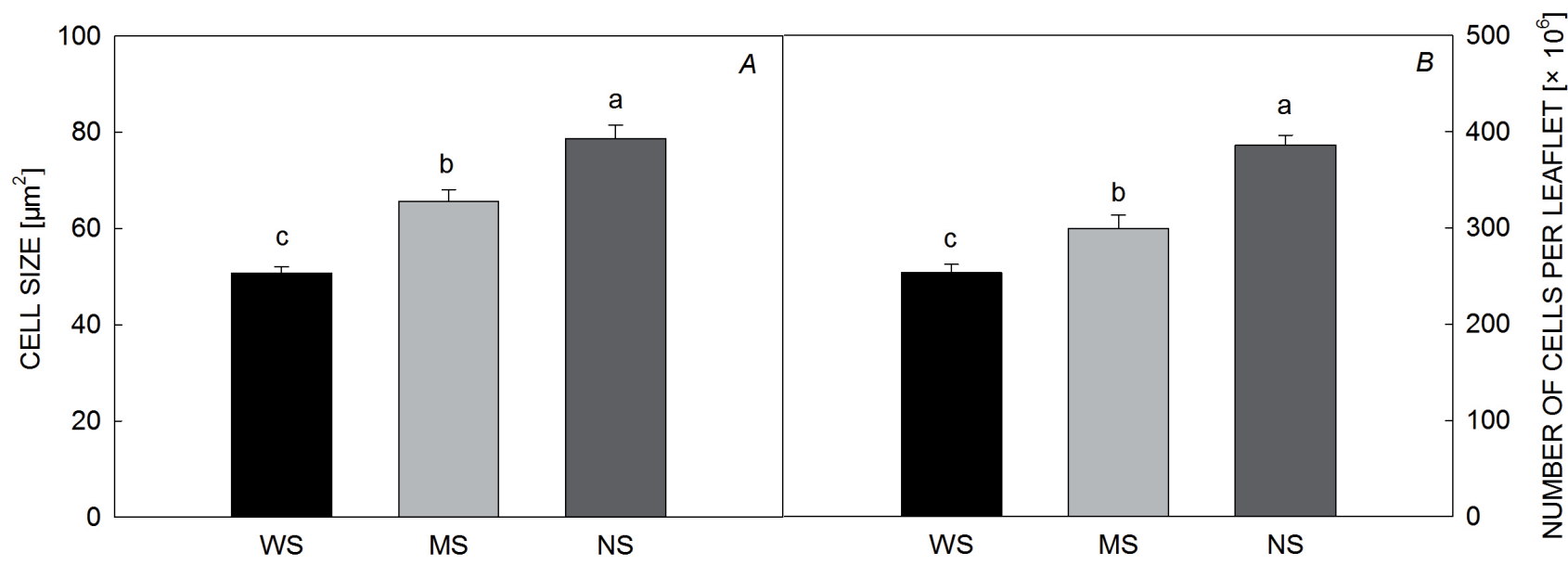

Fig. 4. Cell size $(A)$ and number of cells per leaflet $(B)$ of newly developing leaves during shading treatments. Values are means $\pm \mathrm{SD}$ $(n=3)$. Statistical significance assessed by Duncan's $t$-test. Different lowercase letters mean significant difference at 0.05 level.

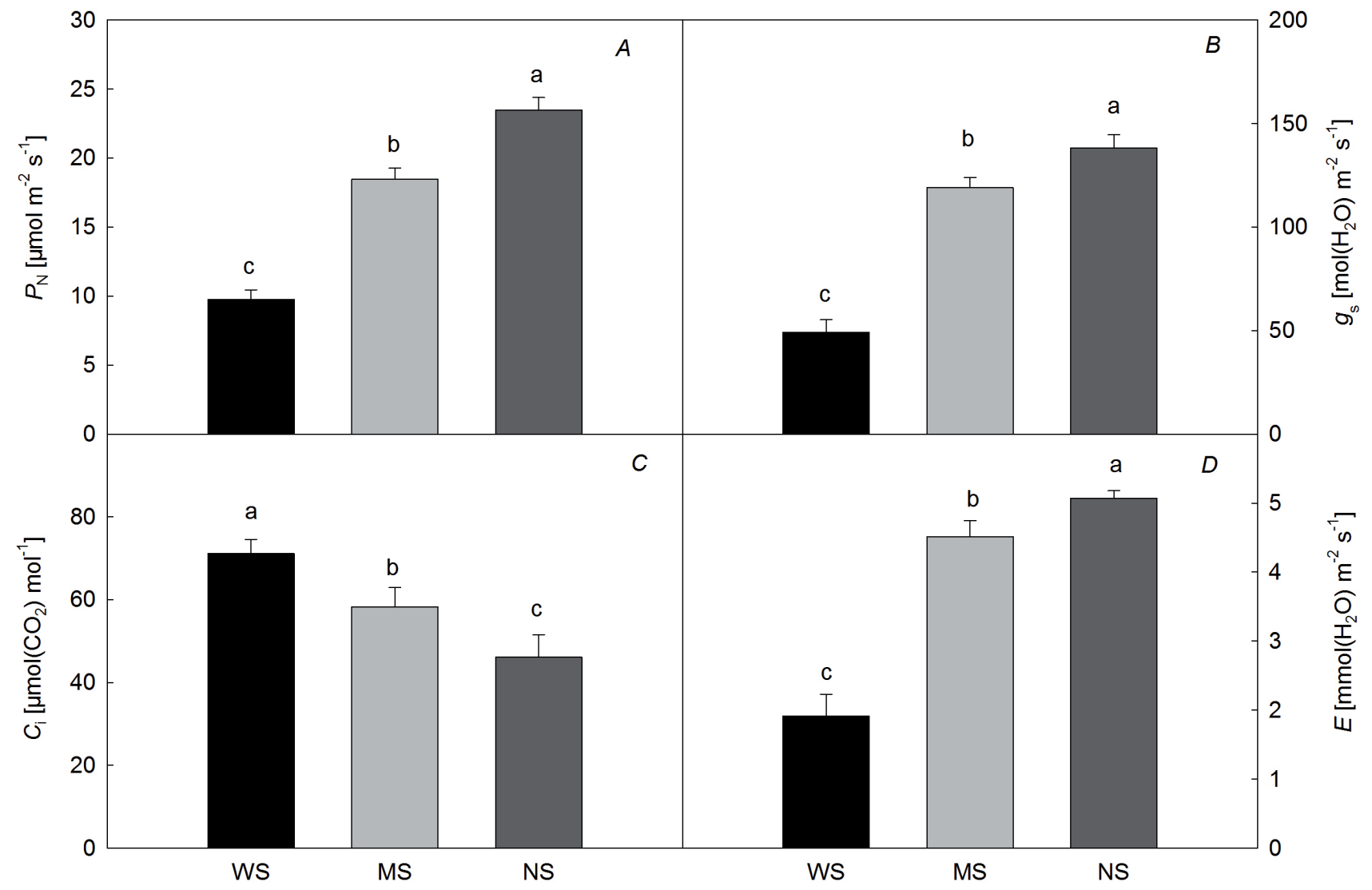

Fig. 5. Net photosynthetic rate $\left(P_{\mathrm{N}}\right)(A)$, stomatal conductance $\left(g_{s}\right)(B)$, carbon dioxide concentration $\left(C_{\mathrm{i}}\right)(C)$, and transpiration rate $(\mathrm{E})$ $(D)$ of newly developing leaves during shading treatments. Values are means $\pm \operatorname{SD}(n=3)$. Statistical significance assessed by Duncan's $t$-test. Different lowercase letters mean significant difference at 0.05 level.

decline in $P_{\mathrm{N}}$ was mainly caused by stomatal limitation (Farquhar and Sharkey 1982). As shown in Fig. 5, the change of $C_{\mathrm{i}}$ was nearly opposite to that of $g_{s}$ under all three treatments. Therefore, this study suggested that the decrease in $P_{\mathrm{N}}$ under shading conditions was caused by nonstomatal rather than stomatal limitations. Additionally, we found that the value of $P_{\mathrm{N}}$ of newly developing leaves under MS were still significantly lower than that under
NS. It was possibly due to a systemic irradiance signal from the mature leaves. Based on the above analysis, we demonstrated that in soybean plants, it is the light environment of the mature leaves which regulates the leaf area and photosynthesis in the newly developing leaves. Therefore, we believe that there is a systemic irradiance signal from the mature leaves to developing leaves in soybean plants, as it has been suggested for other species 


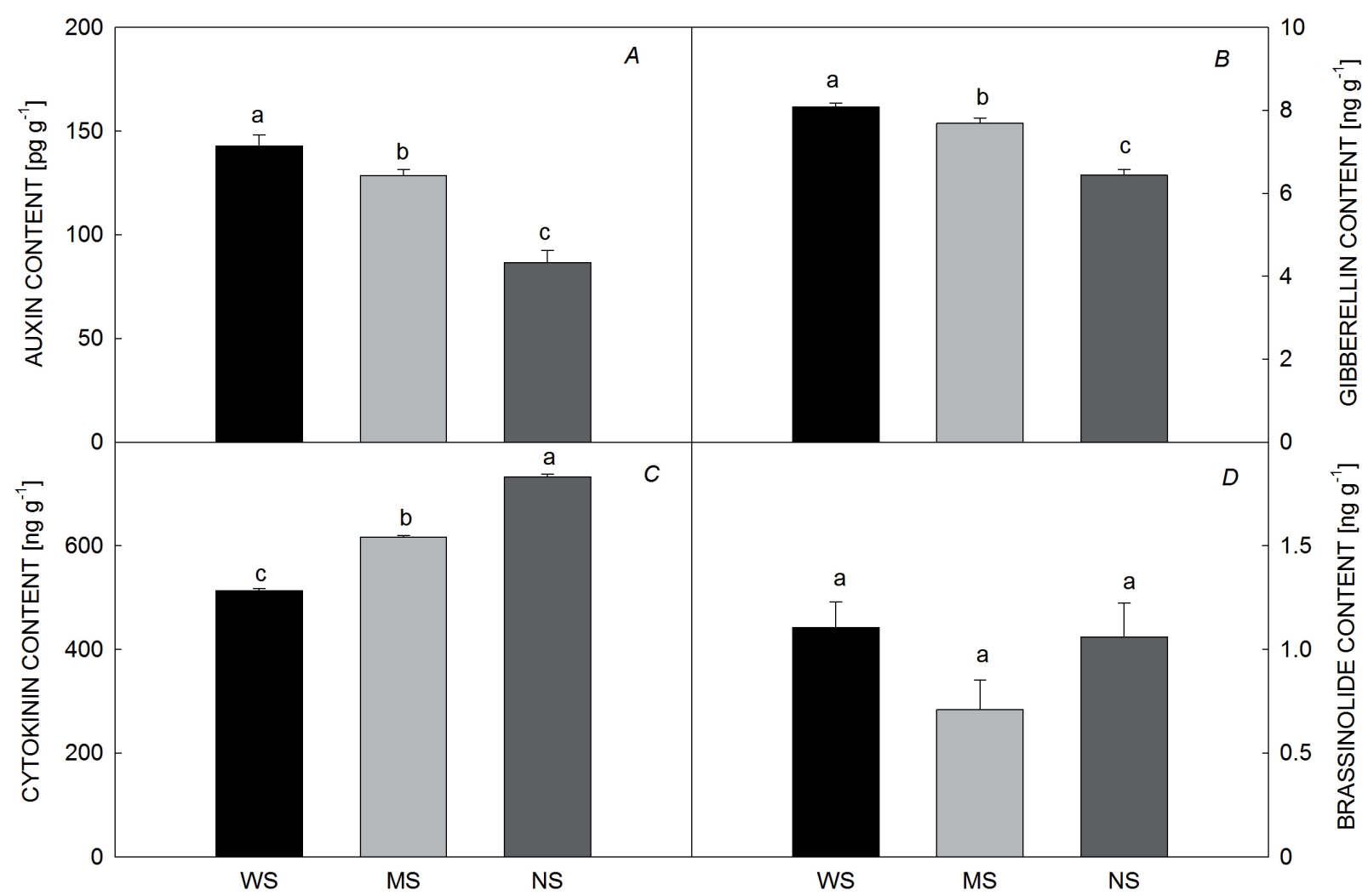

Fig. 6. Auxins $(A)$, gibberellins $(B)$, cytokinins $(C)$, and brassinolides $(D)$ of newly developing leaves during shading treatments. Values are means $\pm \mathrm{SD}(n=3)$. Statistical significance assessed by Duncan's $t$-test. Different lowercase letters mean significant difference at 0.05 level.

(Yano and Terashima 2001, Lake et al. 2002, Thomas et al. 2004, Coupe et al. 2006, Jiang et al. 2011, Murakami et al. 2014, Li et al. 2015).

Several signals have been considered as candidates involved in systemic irradiance regulation, including phytohormones, sugars, redox signaling, microRNAs, and other compounds (fatty acids, abscisic acid) (Kim et al. 2005, Coupe et al. 2006, Guo et al. 2016, Matsuda and Murakami 2016). Among them, phytohormones, such as auxins (Ikeuchi 2011), cytokinins (Kurakawa et al. 2007, Gordon et al. 2009), or gibberellins (Fleet and Sun 2005, Achard et al. 2009) have been long known to play important roles in leaf development. Our previous study has found that shade inhibited leaf area, and auxins, cytokinins, and gibberellins may be involved in leaf development under shade (Gong et al. 2014, Wu et al. 2017). Auxins can regulate leaf development, expansion, and longevity (Keller 2007, Ok et al. 2010, Scarpella et al. 2010), higher concentrations of auxins result in inhibition of cell expansion and in smaller leaves (Keller 2007). Some previous studies proved that shade can increase auxin content in leaves (Vandenbussche et al. 2003, Kurepin et al. 2007). In this study, the auxin content was significantly higher in the newly developing leaves under MS than that of NS and lower than that of WS. This is consistent with previous result that auxin-related genes are involved in systemic irradiance regulation (Coupe et al. 2006). Cytokinins are involved in leaf initiation, shoot apical meristem (SAM) maintenance, and leaf senescence (Werner et al. 2001, Boonman et al. 2006, Kurakawa et al. 2007, Gordon et al. 2009). In this study, we found that the cytokinin content of newly developing leaves decreased in WS. The lower cytokinin contents might induce reduced cell proliferation, which was demonstrated by declined cell numbers. Other previous study also supported this result; shading caused a parallel reduction in the cytokinin concentration (Pons et al. 2001). Although the cytokinin content of newly developing leaves in MS was significantly higher than that of WS, it was still lower than that of NS. This phenomenon indicated that plants can sense the gradual change in the light environment (Pons et al. 2001), and cytokinins are involved in the regulation of whole-plant photosynthetic acclimation to light gradients (Boonman et al. 2007). Thus, we speculate that cytokinins may be involved in leaf development as a systemic irradiance signal. In this study, the smaller leaves in WS showed the significantly higher GA content than the leaves under NS. This is consistent with a suggestion that the shade very likely induced an overall increase in GA biosynthesis in leaves and internodes (Kurepin et al. 2006). The GA content of newly developing leaves in MS was also higher than that of in NS. Combined with its smaller leaves, we speculate that gibberellin may be an important factor to regulate new developing leaf area. In addition, GA and light mainly interact in regulating hypocotyl elongation and stem elongation (Alabadí et al. 2004). Under MS 
treatment, the length of newly developing internode was still higher and internode diameter still lower than that of NS, respectively. This characteristic may also affect the energy transfer from mature leaves to newly developing leaves. Taken together, we suspect that auxins, cytokinins, and gibberellins may be involved in leaf development as a systemic irradiance signal, but we still do not know which hormone plays the most important role and whether they interact with each other. It requires further study in the future.

\section{References}

Achard P., Gusti A., Cheminant S. et al.: Gibberellin signaling controls cell proliferation rate in Arabidopsis. - Curr. Biol. 19: 1188-1193, 2009.

Alabadí D., Gil J., Blázquez M.A.: Gibberellins repress photomorphogenesis in darkness. - Plant Physiol. 134: 1050-1057, 2004.

Avalos G., Mulkey S.S.: Photosynthetic and morphological acclimation of seedlings of tropical lianas to changes in the light environment. - Am. J. Bot. 101: 2088-2096, 2014.

Azevedo G.F.C., Marenco R.A.: Growth and physiological changes in saplings of Minquartia guianensis and Swietenia macrophylla during acclimation to full sunlight. Photosynthetica 50: 86-94, 2012.

Boonman A., Anten N.P., Dueck T.A. et al.: Functional significance of shade-induced leaf senescence in dense canopies: an experimental test using transgenic tobacco. - Am. Nat. 168: 597-607, 2006.

Boonman A., Prinsen E., Gilmer F. et al.: Cytokinin import rate as a signal for photosynthetic acclimation to canopy light gradients. - Plant Physiol. 143: 1841-1852, 2007.

Casal J.J.: Shade avoidance. - Arabidopsis Book 10: e0157, 2012.

Corrẽ W.: Growth and morphogenesis of sun and shade plants. 3. The combined effects of light-intensity and nutrient supply. Act. Bot. Neerl. 32: 277-294, 1983.

Coupe S.A., Palmer B.G., Lake J.A. et al.: Systemic signalling of environmental cues in Arabidopsis leaves. - J. Exp. Bot. 57: 329-341, 2006.

Farquhar G. D., Sharkey T. D.: Stomatal conductance and photosynthesis. - Annu. Rev. Plant Phys. 33: 317-345,1982

Fleet C.M. Sun T.P.: A DELLAcate balance: the role of gibberellin in plant morphogenesis. - Curr. Opin. Plant Biol. 8: 77-85, 2005.

Gong W., Qi P., Du J. et al:: Transcriptome analysis of shadeinduced inhibition on leaf size in relay intercropped soybean. - PLoS ONE. 9: e98465, 2014.

Gong W.Z., Jiang C.D., Wu Y.S. et al.: Tolerance vs. avoidance: two strategies of soybean (Glycine max) seedlings in response to shade in intercropping. - Photosynthetica. 53: 259-268, 2015.

Gordon S.P., Chickarmane V.S., Ohno C. et al.: Multiple feedback loops through cytokinin signaling control stem cell number within the Arabidopsis shoot meristem. - P. Natl. Acad. Sci. USA 106: 16529-16534, 2009.

Guo X.R., Cai K.F., Xu Z.F.: Acclimation to irradiance in seedlings of three tropical rain forest Garcinia species after simulated gap formation. - Photosynthetica 44: 193-201, 2006.

Ikeuchi M., Yamaguchi T., Kazama T. et al.: ROTUNDIFOLIA4 regulates cell proliferation along the body axis in Arabidopsis shoot. - Plant Cell Physiol. 52: 59-69, 2011.

Jiang C.-D., Wang X., Gao H.-Y. et al.: Systemic regulation of leaf anatomical structure, photosynthetic performance, and high-light tolerance in Sorghum. - Plant Physiol. 155: 14161424, 2011.

Karpinski S., Reynolds H., Karpinska B. et al.: Systemic signaling and acclimation in response to excess excitation energy in Arabidopsis. - Science 284: 654-657, 1999.

Keller C. P.: Leaf expansion in Phaseolus: transient auxininduced growth increase. - Physiol. Plantarum 130: 580-589, 2007.

Kim G.T., Yano S., Kozuka T. et al.: Photomorphogenesis of leaves: shade-avoidance and differentiation of sun and shade leaves. - Photochem. Photobio. S. 4: 770-774, 2005.

Kurakawa T., Ueda N., Maekawa M. et al.: Direct control of shoot meristem activity by a cytokinin-activating enzyme. Nature 445: 652-655, 2007.

Kurepin L.V., Emery R.J., Pharis R.P. et al.: Uncoupling light quality from light irradiance effects in Helianthus annuus shoots: putative roles for plant hormones in leaf and internode growth. - J. Exp. Bot. 58: 2145-2157, 2007.

Kurepin L.V., Pharis R.P., Reid D.M. et al.: Involvement of gibberellins in the stem elongation of sun and shade ecotypes of Stellaria longipes that is induced by low light irradiance. Plant Cell Environ. 29: 1319-1328, 2006.

Lake J., Quick W., Beerling D. et al.: Plant development: signals from mature to new leaves. - Nature 411: 154, 2001.

Lake J.A., Woodward F.I., Quick W.P.: Long-distance $\mathrm{CO}_{2}$ signalling in plants. - J. Exp. Bot. 53: 183-193, 2002.

Li T., Liu Y., Shi L. et al.: Systemic regulation of photosynthetic function in field-grown sorghum. - Plant Physiol. Bioch 94: 86-94, 2015.

Lim P.O., Lee I.C., Kim J. et al.: Auxin response factor 2 (ARF2) plays a major role in regulating auxin-mediated leaf longevity. - J. Exp. Bot. 61: 1419, 2010.

Liu X., Rahman T., Song C. et al.: Changes in light environment, morphology, growth and yield of soybean in maize-soybean intercropping systems. - Field Crops Res. 200: 38-46, 2017.

Matsuda R. and Murakami: Light- and $\mathrm{CO}_{2}$-dependent systemic regulation of photosynthesis. - Prog. Bot. 77: 151-166, 2016.

Miyazawa S., Livingston N.J., Turpin D.H.: Stomatal development in new leaves is related to the stomatal conductance of mature leaves in poplar (Populus trichocarpa $\times$ P. deltoides). $-\mathrm{J}$. Exp. Bot. 57: 373-380, 2006.

Murakami K., Matsuda, R., Fujiwara K.: Light-induced systemic regulation of photosynthesis in primary and trifoliate leaves of Phaseolus vulgaris: effects of photosynthetic photon flux density (PPFD) versus spectrum. - Plant Biol. 16: 16-21, 2014.

Pons T.L., Jordi W., Kuiper D.: Acclimation of plants to light gradients in leaf canopies: evidence for a possible role for cytokinins transported in the transpiration stream. - J. Exp. Bot. 52: 1563-1574, 2001.

Rodríguez-López N.F., Martins S.C., Cavatte P.C. et al.: Morphological and physiological acclimations of coffee seedlings to growth over a range of fixed or changing light supplies. - Environ. Exp. Bot. 102: 1-10, 2014.

Scarpella E., Barkoulas M., Tsiantis M.: Control of leaf and vein development by auxin. - Cold Spring Harb. Perspect. Biol. 2: a001511, 2010.

Schoch P., Zinsou C., Sibi M.: Dependence of the stomatal index on environmental factors during stomatal differentiation in leaves of Vigna sinensis L. 1. Effect of light intensity. - J. Exp. Bot. 31: 1211-1216, 1980.

Thomas P.W., Woodward F.I., Quick W.P.: Systemic irradiance signalling in tobacco. - New Phytol. 161: 193-198, 2004.

Vandenbussche F., Vriezen W.H., Smalle J. et al: : Ethylene and auxin control the Arabidopsis response to decreased light 
intensity. - Plant Physiol. 133: 517-527, 2003.

Werner T., Motyka, V., Strnad, M. et al.: Regulation of plant growth by cytokinin. - P. Natl. Acad. Sci. USA 98: 1048710492, 2001.

Wu Y., Gong W. Yang W.: Shade inhibits leaf size by controlling cell proliferation and enlargement in soybean. - Sci Rep.-UK 7: 9259, 2017.

Wu Y. S., Gong W. Z., Yang F. et al.: Response to shade and subsequent recovery of soya bean in maize- soya bean relay strip intercropping. - Plant Prod. Sci. 19: 206-214, 2015. Yang F., Liao D., Wu X. et al.: Effect of aboveground and belowground interactions on the intercrop yields in maizesoybean relay intercropping systems. - Field Crops Res. 203:
16-23, 2017.

Yang F., Wang X., Liao D. et al.: Yield response to different planting geometries in maize-soybean relay strip intercropping systems. - Agron. J. 107: 296-304, 2015.

Yang J., Zhang J., Huang Z. et al.: Correlation of cytokinin levels in the endosperms and roots with cell number and cell division activity during endosperm development in rice. - Ann. Bot.London 90: 369-377, 2002.

Yano S., Terashima I.: Separate localization of light signal perception for sun or shade type chloroplast and palisade tissue differentiation in Chenopodium album. - Plant Cell Physiol. 42: 1303-1310, 2001.

(C) The authors. This is an open access article distributed under the terms of the Creative Commons BY-NC-ND Licence. 